\title{
Late-Stage Non-Anastomotic Rupture of Axillo-Bifemoral Bypass Graft
}

\author{
Manabu Shiraishi, MD, Chieri Kimura, MD, Taro Takeuchi, MD, and \\ Kenichi Muramatsu, MD
}

\begin{abstract}
An 82-year-old woman, who underwent axillo-bifemoral bypass for infrarenal aortic occlusion and peripheral arterial occlusive disease 9 years before, was admitted to our hospital for swelling in the left subclavicular region. Ultrasound examination revealed a leak in the wall of the bypass graft with the formation of a false aneurysm. No signs of infection, either locally or systemically, were observed. Resection of the aneurismal segment with interposition using a Dacron graft was performed. Macroscopic findings during surgery confirmed an intact anastomotic region of the left axillary artery and Dacron graft. Two possible mechanisms for the formation of this false aneurysm, either cumulative stress on the graft over the years or Dacron graft biodegradation, were hypothesized.
\end{abstract}

Keywords: false aneurysm, axillo-bifemoral bypass, Dacron graft

\section{Introduction}

An axillo-femoral graft has been used in the treatment of peripheral arterial occlusive disease. Cases of the formation of a false lumen after this surgery have been reported previously. ${ }^{1-6)}$ Most of them were due to disruption of proximal anastomosis and false aneurismal formation at the site, rather than in the anastomotic region, has been rarely reported. In this case report, we present a case of a false aneurysm of an axillo-femoral bypass and discuss possible causes and risk factors.

\section{Case Report}

An 82-year-old woman was admitted to our hospital for swelling in the left subclavicular region. She has a

$\overline{\text { Division of Cardiovascular Surgery, Saitama Red-cross Hospital, }}$ Saitama, Saitama, Japan

Received: October 20, 2011; Accepted: November 14, 2011 Corresponding author: Manabu Shiraishi, MD. Division of Cardiovascular Surgery, Saitama Red-Cross Hospital, 8-3-33 Kamiochiai, Chyuo-ku, Saitama, Saitama 338-8553, Japan Email: manabu@omiya.jichi.ac.jp

(C)2012 The Editorial Committee of Annals of Thoracic and Cardiovascular Surgery. All rights reserved. history of infrarenal aortic occlusion and peripheral arterial occlusive disease with severe claudication, for which she underwent an implantation of a 10-mm woven Dacron axillo-bifemoral bypass at the age of 73 years. Upon physical examination, a $70-\mathrm{mm}$ by $50-\mathrm{mm}$ by $60-\mathrm{mm}$ pulsatile, erythematous, indolent mass with distinctly palpable thrill was observed in the left subclavicular region (Fig. 1a). There was no tenderness over the mass. She noticed this mass 6 months before, which had suddenly grown in the past two or three months. There were no signs of infection, either systemically or locally, and hematologic parameters also supported no indication of infection. Ultrasound examination with color duplex sonography showed normal blood flow in the bypass graft. However, a leak from the bypass wall was detected in the region of the pulsatile mass with the formation of a false aneurysm. Computed Tomography (CT) revealed rupture of the left axillo-bifemoral bypass graft with formation of a false lumen, but the anastomotic region of the left axillary artery and Dacron graft remained intact (Fig. 1b and 1c). Based on the results of those studies, resection of the aneurismal segment and interposition with Dacron graft was planned. The macroscopic finding of the old incision confirmed that the anastomotic region of the left axillary artery and Dacron graft was intact. The new incision over 


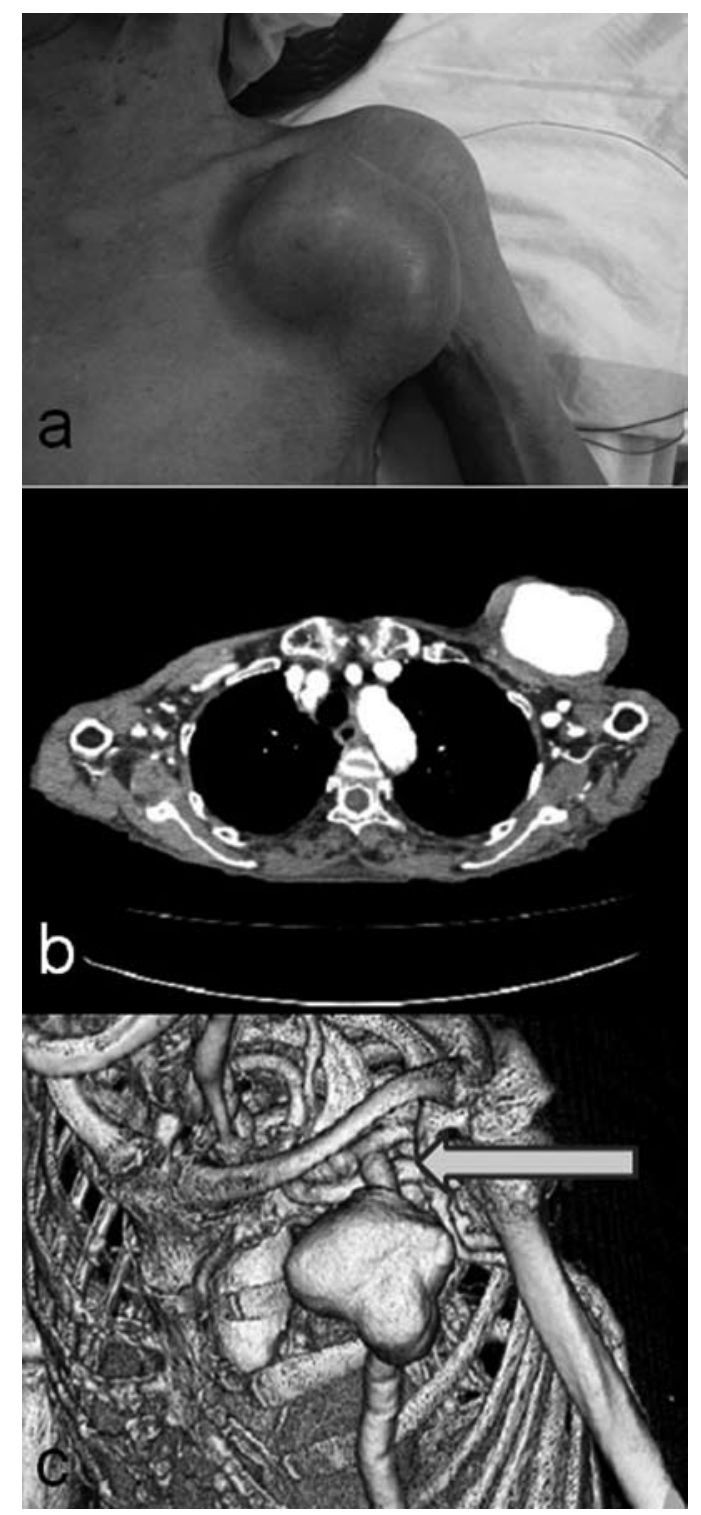

Fig. 1 (a) A 70- $\mathrm{mm}$ by $50-\mathrm{mm}$ by $60-\mathrm{mm}$ pulsatile, erythematous, indolent mass was detected in the left subclavicular region. (b) Computed tomography revealed rupture of the left axillo-bifemoral bypass graft with formation of a false aneurysm. (c) In the reconstructed computed tomography, a white arrow denotes an anastomotic region of the left axillary artery and Dacron graft was intact.

the mass exposed a false aneurysm that was formed by a fibrous sheath around the ruptured Dacron graft. Hemostasis was achieved by clamping both proximal and distal sides of the graft. The 50-mm longitudinally-cracked Dacron graft (Fig. 2) was then replaced with a $10-\mathrm{mm}$ woven Dacron graft, and the proximal and the distal anastomoses were incorporated into each portion of the previous axillo-femoral graft, which was still patent. The postoperative course was uneventful, and ultrasound ex-

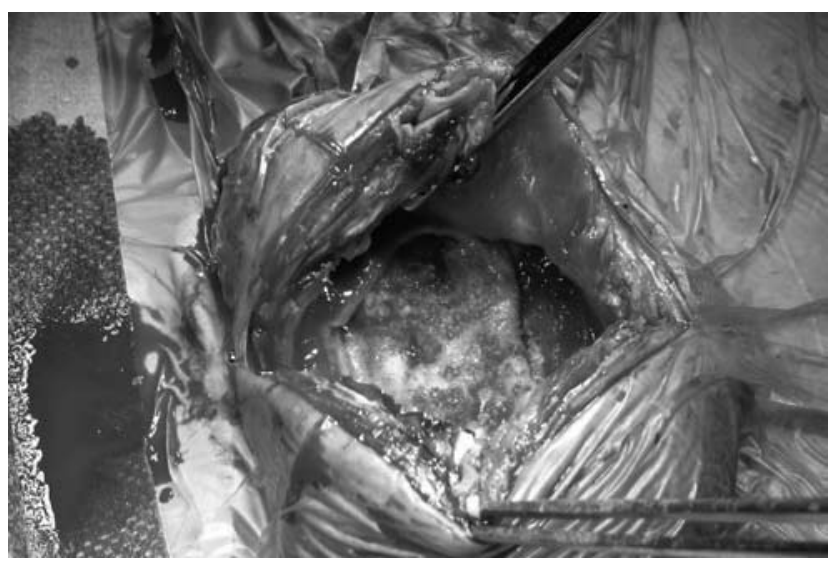

Fig. 2 Dacron graft was 50-mm longitudinally-cracked.

amination after surgery proved that there was sufficient flow into the bifemoral artery through the bypass.

\section{Discussion}

A false aneurysm is a saclike structure that communicates with the arterial lumen, caused by focal perforation with all layers of the disrupted arterial wall and escaped blood contained by adventitia, perivascular connective tissue, and organized blood clot.7) In this case report, we described a patient who developed a saccular-type false aneurysm of an axillo-femoral bypass, far from the initial operation. The formation of an aneurysm or a false aneurysm occurs rarely, with incidence of 5\%-10\%. ${ }^{1,8)}$ False aneurysm is a known complication that can appear in the anastomotic site of the graft and are mostly traumatic in origin; this is known as "pullout syndrome" because it involves the overextension of the arm with subsequently increased distance from the axillary artery to the femoral artery. ${ }^{3,7)}$ Other causes of false aneurysm are reported as infection, trauma other than pullout syndrome, and biodegradation of fibers by fluids of tissue enzymes. ${ }^{3,79)}$ Whereas, the formation of the false aneurysm in the region, rather than anastomotic site as in our case, is extremely rare, and only four cases of false aneurysms of the graft far from anastomosis have been published. Of these, two were caused by trauma, ${ }^{3,4)}$ one was due to a technical error resulting from applying a too short bypass with the overextension of the graft and disruption. ${ }^{5)}$ No definitive cause was established in the remaining one. ${ }^{6}$ As there were no clear events in the history of the patient that might have precipitated the disruption of the graft, we speculate the causes of the disruption as the effect of cumulative stress on the graft over the years, which 
reached a critical point at which the graft was torn, or Dacron graft biodegradation, or intra-operative clamp injury on this remote graft laceration. Unfortunately, we did not send the excised, old Dacron graft to microscopic or electron microscopic examination to investigate the cause of the late-stage graft disruption.

False aneurysms at the anastomosis usually emerge within a few weeks after surgery. The late disruption is unlikely to occur as fibrous tissue ingrowth, which is thought to stabilize the anastomosis beyond the critical early weeks of surgery. ${ }^{1)}$ With the improved patency rates and the longer life expectancy of many of patients who received this surgery, awareness of this immediate lifethreatening complication is critical.

\section{Conclusion}

We recommend continuous long-term follow-up of patients with Dacron grafts to confirm no late aneurismal formation.

\section{Disclosure Statement}

The authors have no conflicts of interest to declare. No external funding was obtained for the work presented here.

\section{References}

1) Oshodi TO, Abraham JS, Kelly JF. Axilla false aneurysm following late anastomotic disruption of an old axillofemoral bypass graft. Eur J Vasc Endovasc Surg 2000; 20: 492-3.

2) Yamamoto K, Yoshimura T, Ohtani S. False aneurysm of the axillary artery caused by graft infection: report of a case. Surg Today 1997; 27: 376-8.

3) Krüger K, Landwehr P, Kristen F, et al. Unusual pseudoaneurysm of an axillofemoral bypass caused by seat belt trauma: case report. J Trauma 1999; 46: 18991.

4) Buche M, Noirhomme P, Devaux P, et al. Posttraumatic false aneurysm of axillofemoral bypass graft. J Vasc Surg 1992; 16: 498-500.

5) Akiyama K, Hirota J, Shiina Y, et al. Thrombotic obstruction of a reinforced ringed expanded polytetrafluoroethylene graft caused by formation of a pseudoaneurysm at a nonanastomotic site: report of a case. Surg Today 1996; 26: 936-9.

6) Piazza D, Ameli FM, von Schroeder HP, et al. Nonanastomotic pseudoaneurysm of expanded polytetrafluoroethylene axillofemoral bypass graft. J Vasc Surg 1993; 17: 777-9.

7) Oz BS, Yilmaz AT, Gunay C, et al. True aneurysm formation in axillofemoral bypass with a reinforced ePTFE graft-a case report. Vasc Endovascular Surg 2002; 36: 327-9.

8) Alexander RH, Selby JH. Axillofemoral bypass grafts using polytetrafluoroethylene. South Med J 1980; 73: 1325-9.

9) Cheshire NJ, Barrie WW. Late false aneurysm formation along an axillobifemoral graft. Eur J Vasc Surg 1991; 5: 693-4. 